\title{
23
}

\section{Finding Solutions to Sanitary Sewer System Capacity Deficiencies}

\author{
Derek Wride, Joe Koran, Mi Chen, Ben Gamble and Edward \\ H. Burgess
}

In 2000, the Metropolitan Sewer District of Greater Cincinnati (MSDGC) initiated the development of a system-wide computer model (SWM) of their wastewater collection system to assist the agency in the assessment of the hydraulic performance of its system and in the prioritization of short- and long-term system improvements. The 42,000-node SWM was developed and calibrated, using EPA SWMM 4, over a three-year period and represents over 1,500 miles of pipe (CDM, 2003).

In response to Consent Decree requirements, the SWM was used to perform a comprehensive hydraulic capacity assessment to identify system deficiencies of the wastewater collection system under both dry- and wetweather flow conditions. More recently, the SWM has been applied to find solutions to hydraulic deficiencies in order to provide adequate system capacity under present and future conditions.

This chapter presents the process used to develop a solution to hydraulic capacity deficiencies in the Mill Creek Basin of the MSDGC sanitary service area. The general approach using SWMM modeling techniques to screen alternatives and find cost-effective solutions are discussed, including a tool

Wride, D., J. Koran, M. Chen, B. Gamble and E. Burgess. 2007. "Finding Solutions to Sanitary Sewer System Capacity Deficiencies." Journal of Water Management Modeling R227-23. doi: 10.14796/JWMM.R227-23. (C) CHI 2007 www.chijournal.org ISSN: 2292-6062 (Formerly in Contemporary Modeling of Urban Water Systems. ISBN: 0-9736716-3-7) 
created to read SWMM output files and generate planning level costs. The costing is based on agreed upon costing curves for the project and is applied for a particular scenario based on the difference in pipe sizes needed for various scenarios. The costing tool provided an efficient means to estimate costs and expedited the alternative screening process. The process led to approximately $\$ 300 \mathrm{M}$ in sanitary sewer capital improvement projects that are currently being considered as a component to the agency's Wet Weather Improvement Plan.

\subsection{Introduction}

\subsubsection{Consent Decrees}

The Metropolitan Sewer District of Greater Cincinnati (MSD) began negotiations in 1997 with the Department of Justice, the U.S. Environmental Protection Agency, and the State of Ohio to address sanitary sewer overflows (SSOs) and combined sewer overflows (CSOs). Negotiations resulted in two Consent Decrees; the Interim Partial Consent Decree on SSOs (United States of America and the State of Ohio, 2002) followed by the Global Consent Decree (United States of America and the State of Ohio, 2003).

In anticipation of the impending consent decree requirements, as well as Capacity, Management, Operations and Maintenance (CMOM) regulations, Cincinnati MSD initiated a sewer modeling program to support its regulatory compliance efforts. This program began with the development and calibration of a computer model that could be used to study and understand the hydraulic performance of their wastewater collection system.

In 2000, the Metropolitan Sewer District of Greater Cincinnati (MSDGC) initiated the development of a system-wide computer model (SWM) of their wastewater collection system to assist the agency in the assessment of the hydraulic performance of its system and in the prioritization of short- and long-term system improvements. The 42,000node SWM was developed and calibrated, using EPA SWMM 4 (Huber, $1988)$ over a three-year period and represents over 1,500 miles $(2400 \mathrm{kms})$ of pipe with a diameter above $12 \mathrm{in.}(305 \mathrm{~mm})$ for sanitary sewers and $18 \mathrm{in}$. (457 mm) for combined sewers (CDM, 2003).

In response to Consent Decree requirements (United States of America, $2002 \& 2003$ ), the SWM was used to perform a comprehensive hydraulic 
capacity assessment of the wastewater collection system under both dry- and wet-weather flow conditions and is currently being applied to find solutions to assure system capacity. The SWM has been integrated into the agency operations and is being applied to meet a variety of objectives, some of which will extend well into the future.

\subsubsection{MSD Service Area}

The MSDGC serves over 800,000 customers in Hamilton County, Ohio covering approximately $410 \mathrm{mi}^{2}\left(1,059 \mathrm{~km}^{2}\right)$ of which about $257 \mathrm{mi}^{2}$ $\left(664 \mathrm{~km}^{2}\right)$ are currently sewered. The service area is divided into three major drainage basins; the Mill Creek Basin, the Little Miami Basin, and the Great Miami Basin. The collection system consists of over 3,000 miles $(4,825 \mathrm{~km})$ of sanitary and combined sewers that flow to one of seven major wastewater treatment plants. Within the collection system are approximately $85 \mathrm{SSO}$ and $230 \mathrm{CSO}$ points. Figure 23.1 is bounded by the Hamilton County, Ohio lines and illustrates the three major drainage basins.

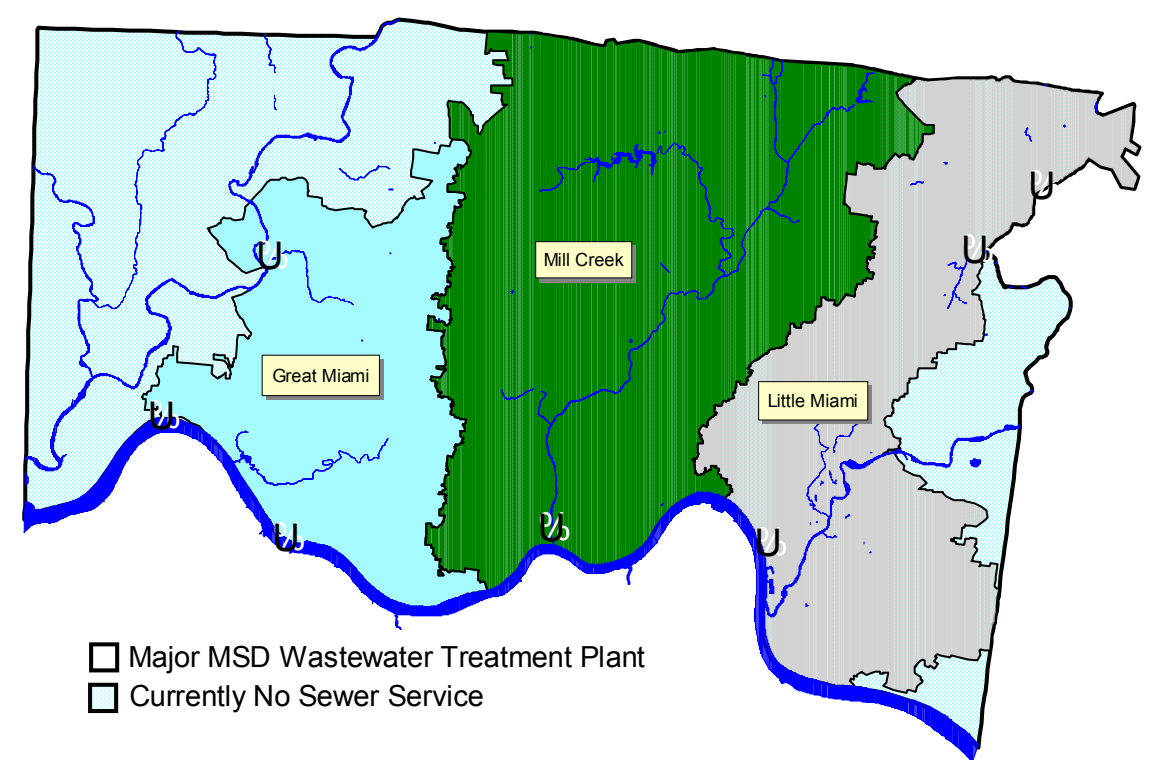

Figure 23.1 MSDGC service area-3 major drainage basins. 


\subsubsection{Mill Creek Service Area}

The Mill Creek Basin is the largest of the three major drainage basins located in the central area of the county and covering approximately $115 \mathrm{mi}^{2}$ $\left(297 \mathrm{~km}^{2}\right), 45 \%$ of the total sewered area. The Little Miami Basin is adjacent to the Mill Creek Basin on the East while the Great Miami Basin borders on the West. Within the Mill Creek Basin are three primary subbasins; the East Branch, the West Branch, and the South Mill Creek area. The collection system in the East and West Branches consists almost entirely of separate sanitary sewers while the South Mill Creek area is predominantly a combined sewered area. The Mill Creek passes through the entire 17-mile $(27-\mathrm{km})$ length of the basin from the north to the Ohio River on the South. Fifty-two of the $85 \mathrm{SSO}$ are located within the 1,722-mile $(2,892-\mathrm{km})$ collection system. Figure 23.2 illustrates the three sub-basins within the Mill Creek Basin as well as the Mill Creek, SSOs and CSOs.

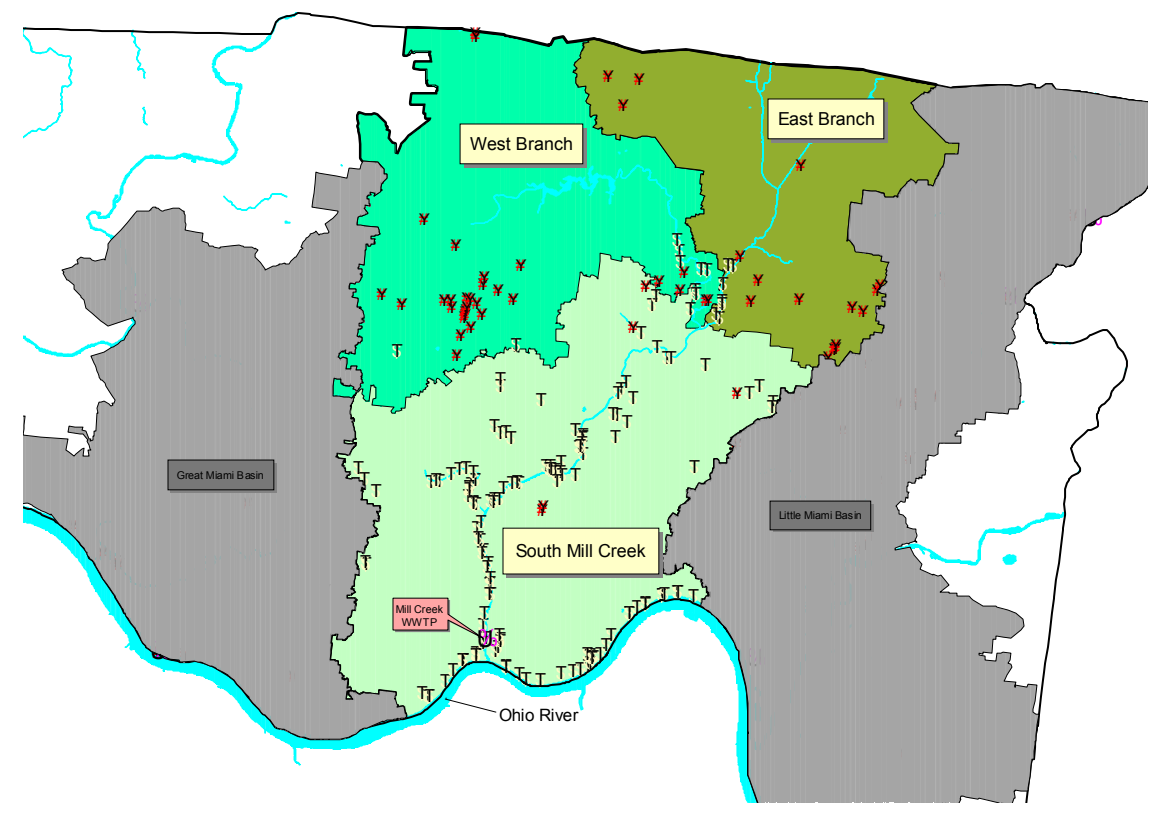

Figure 23.2 Three sub-basins of Mill Creek drainage basin with SSOs (circles) and CSOs (triangles). 


\subsubsection{Capacity Assessment Summary}

Using the fully dynamic and calibrated system-wide model, a comprehensive, hydraulic capacity assessment was performed of the agency's wastewater collection system for both dry-weather and various wet-weather conditions. Capacity deficiencies were identified by the design storm level (6-month, 2-y, 5-y, or 10-y) at which the manholes began to surcharge. Figure 23.3 is an illustration of the capacity assessment results for one of the approximate 300 sewersheds across the MSDGC service area. Pipe surcharging can be clearly viewed in relation to the system SSOs as well as capacity related water-in-basement complaints. The complete hydraulic capacity assessment results are documented in an 8-volume, 2,251-page report.

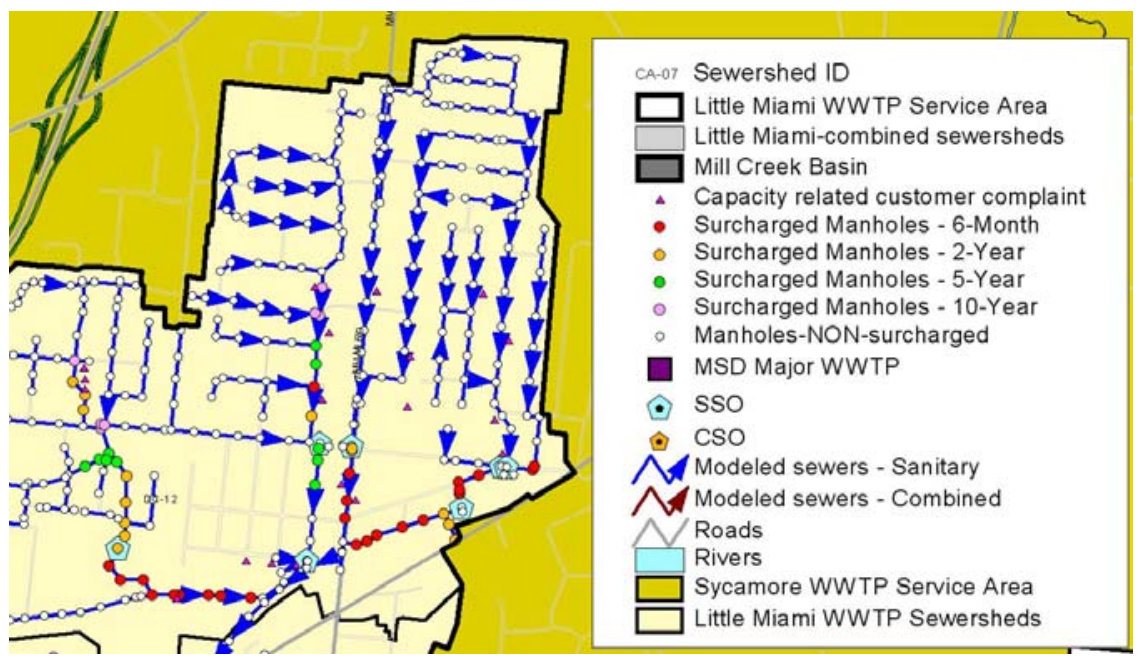

Figure 23.3 Capacity assessment results for a sample sewershed.

\subsubsection{Problem Areas - Sanitary Sewer System}

The capacity assessment results indicate that surcharging conditions exist at some level of design storm across the entire system. Surcharging is defined as where the water depth in a manhole is greater than the crown of the pipe entering or leaving the manhole. Isolated surcharging conditions are not 
likely to cause problems, such as manhole flooding or water-in-basement conditions. Problem areas were identified as reaches of the sewer system where there was a consecutive number of surcharging manholes (ten or more). This grouping was the basis to begin finding solutions to the hydraulic capacity deficiencies. The problem areas were found to be widespread across the entire collection system and not concentrated in any particular region. Figure 23.4 illustrates the problem areas across the sanitary sewered areas of the Mill Creek Basin.

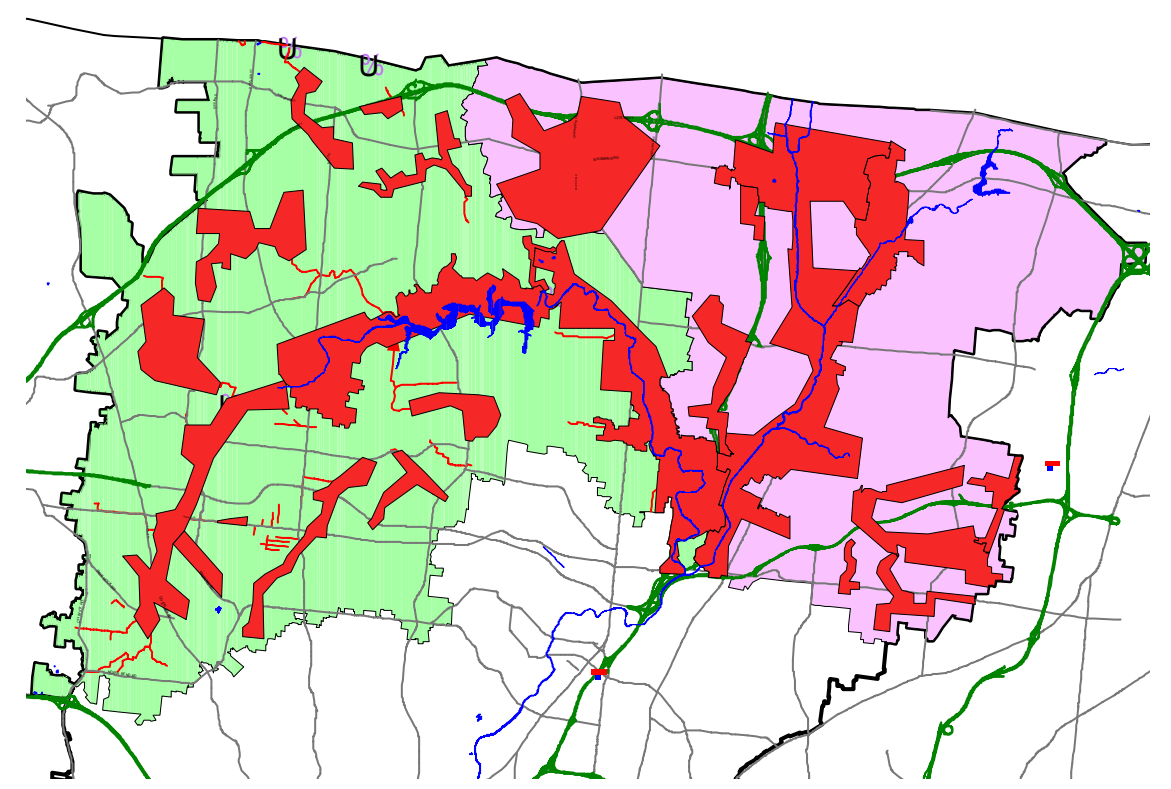

Figure 23.4 Mill Creek Basin sanitary sewer capacity problem areas (dark shaded polygons).

\subsection{Approach}

An approach was developed to enable a methodical means to find solutions to the hydraulic capacity deficiencies across the Mill Creek Basin. Figure 23.5 illustrates the overall approach showing the process and primary tools used, which are described in more detail in section 23.2.2. 
$\underline{\text { Tools }}$

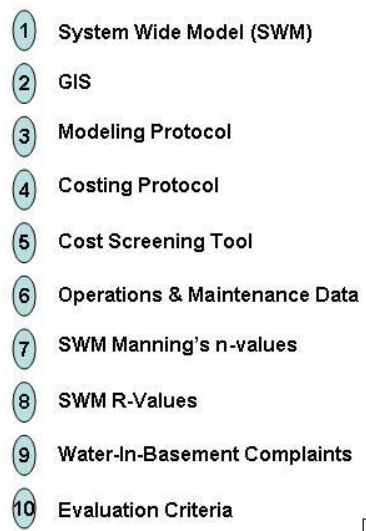

Process

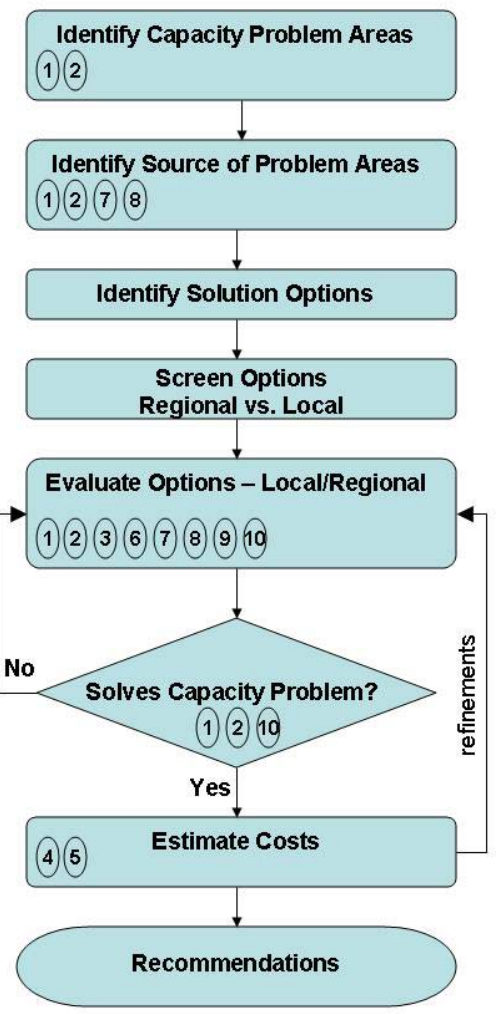

Figure 23.5 Overall approach - process and tools used.

After the capacity problems and their causes were identified, the approach started with a broad view and continued through a screening and refining process that narrowed to the final recommended solutions. One of the initial steps was to organize the problem areas into regional and local areas. Figure 23.6 illustrates the pipes that belong to the local and regional areas, where the regional sewers are 18 in. in diameter and larger.

A set of options representing possible technologies and methods to solve the capacity deficiencies was identified. With the options identified, a screening process was employed. The results from the screening process were tested for both the regional and local solutions. As solutions were developed, refinements were evaluated where warranted until a set of solutions was identified and the individual projects prioritized. 


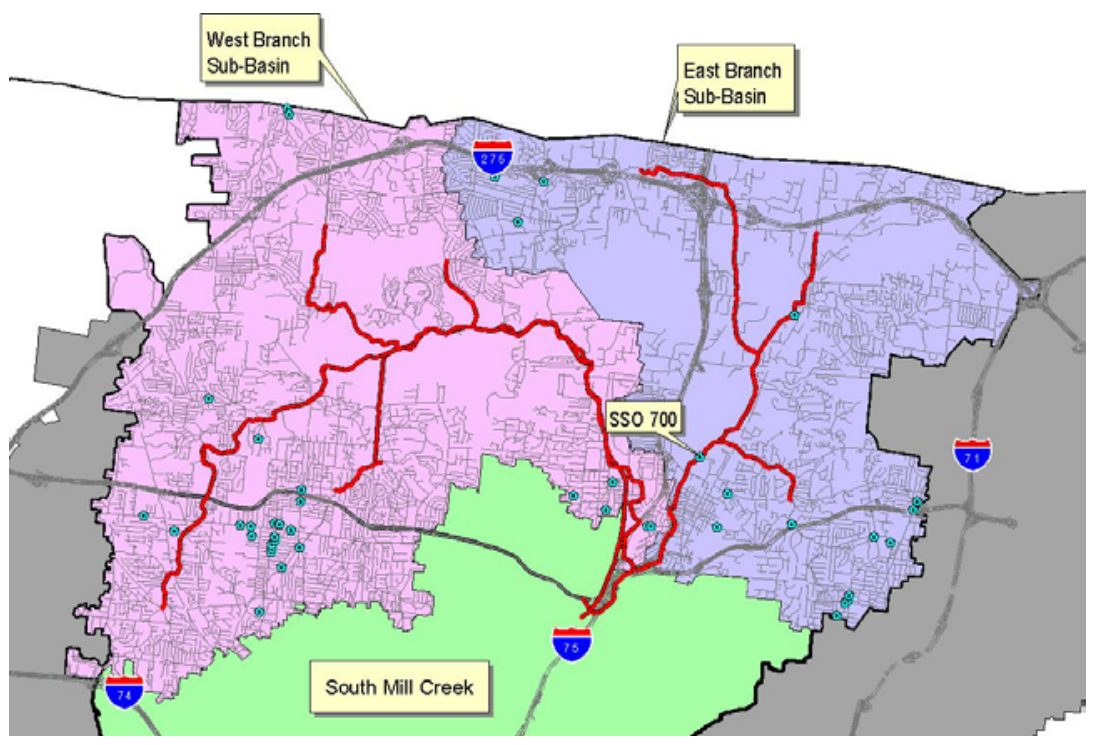

Figure 23.6 Regional (thick, dark colored) and local sewers (thin, dark colored) in the sanitary area of the Mill Creek Basin.

\subsubsection{Options}

A set of options was identified that could potentially offer solutions to the hydraulic capacity deficiencies. Below is a list of the options considered.

1. conveyance enhancements

2. storage

3. I/I reduction

4. pumping

5. treatment

6. real-time controls

Table 23.1 lists the options considered and identifies whether each could offer a regional or local option and whether or not it could solve all of the problems independent of other options. Because the team had a good understanding of the system, the compilation of the table served as part of the screening process before any modeling was performed. 
Table 23.1 Options to solve capacity deficiencies.

\begin{tabular}{|c|c|c|c|}
\hline Option & $\begin{array}{l}\text { Regional } \\
\text { option? }\end{array}$ & $\begin{array}{c}\text { Local } \\
\text { option? }\end{array}$ & $\begin{array}{l}\text { Needs other } \\
\text { option? }\end{array}$ \\
\hline \multicolumn{4}{|c|}{ Conveyance Capacity Enhancement } \\
\hline upsizing existing pipes & yes & yes & yes \\
\hline new parallel/relief sewer & yes & yes & yes \\
\hline adding express sewer & yes & yes & yes \\
\hline cleaning existing pipes & yes & yes & yes \\
\hline \multicolumn{4}{|l|}{ Equalization Storage } \\
\hline surface (on/near surface) & yes & yes & yes \\
\hline deep tunnel storage & yes & no & yes \\
\hline \multicolumn{4}{|l|}{ Treatment } \\
\hline expand Mill Creek WWTP & yes & no & yes \\
\hline build new WWTP & yes & no & yes \\
\hline expand HRT facility & yes & no & yes \\
\hline Add new HRT facility & yes & no & yes \\
\hline \multicolumn{4}{|l|}{ I/I Reduction } \\
\hline reduce public I/I source & yes & yes & yes \\
\hline reduce private $\mathrm{I} / \mathrm{I}$ source & no & yes & yes \\
\hline \multicolumn{4}{|l|}{ Real-Time Controls } \\
\hline Use existing control structures & yes & no & yes \\
\hline Add new control structures & yes & no & yes \\
\hline \multicolumn{4}{|l|}{ Pumping } \\
\hline increase existing pumping & no & yes & yes \\
\hline Add new pump stations & yes & yes & yes \\
\hline
\end{tabular}

\subsubsection{Tools}

Various tools and data were used to accomplish the task of finding solutions to the sanitary sewer system capacity deficiencies. The more significant tools and data used for the project and a brief description of their significance are described below.

\section{System Wide Model - SWMM EXTRAN routing}

- The SWM was the central tool for evaluating the effectiveness of the various options and combination of options on solving system hydraulic deficiencies. The SWM represents a detailed description of the Mill Creek collection system and drainage area. It includes pipes that are 12 in. in 
diameter and greater. Flow was estimated and input to the model from 15,472 subcatchments covering the 73,430 acres $(29,850$ ha)of served area, which averages about 4.75 acres $(1.9 \mathrm{ha}) /$ subcatchment. Based on the developed SWM, the following four separate models were created to assist with the work:

1. a model of the entire Mill Creek Basin - used to assess capacity problems, define boundary conditions for subbasin models, and verify final recommendations seamlessly;

2. a model of the West Branch Subbasin - since the subbasin is largely hydraulically independent from the East Branch Subbasin, the decreased model size led to significantly shorter model run-times;

3. a model of the East Branch Subbasin - since the subbasin is largely hydraulically independent from the West Branch Subbasin, the decreased model size led to significantly shorter model run-times; and

4. a model of the South Branch with the trunk sewers from the East and West Branch Subbasins.

GIS

The use of GIS technology was valuable to visualize the location of the capacity deficiencies system-wide, integrate the relevant agency data into the planning process, and communicate the results of the planning effort throughout the process with the agency and other involved stakeholders. Using GIS technology helped to quickly visualize how the application of different potential solution options in the local and regional systems might influence each other. Working in a GIS environment also provided the capability to quickly determine if the solutions being evaluated were addressing nearby areas experiencing water-in-basement complaints, which was a key objective of the study. It was also fundamental to being able to quickly and efficiently communicate results and information via hard-copy and electronic maps and graphics to the client and other team members.

\section{Modeling Protocol}

A modeling protocol was provided by the agency to all members of the team involved in the planning efforts, including the other two major drainage basins. The protocol provided guidance so that all team members would use the SWM in a consistent manner to evaluate the different options evaluated. 
How to represent the different options (e.g. storage, relief pipes, etc.) to solve the capacity problems in the model was important in order to reduce the likelihood of the model generating different results.

\section{Costing Protocol}

A costing protocol was provided by the agency to all members of the team involved in the planning efforts, including the other two major drainage basins, to provide a consistent approach to costing the solutions. Standard costing curves led to a higher level of confidence in the estimated costs across all basins and to a more consistent level of detail for the costing.

\section{Cost Screening Tool}

A costing tool was developed that used the costing information provided in the Costing Protocol to quickly screen the numerous potential solutions. The tool reads model output data from the SWM runs and applies the costing curve data to the solutions used in the corresponding model run. This tool quickly identiiedy a cost estimate for each solution involving conveyance improvements, without the laborious and detailed costing effort required in the Costing Protocol for the final costing. The tool reads the SWMM output files representing a before and after scenario (involving conveyance improvements), compares the pipes and their attributes, and identifies the differences in pipe attributes (or new pipes). Based on these, the tool calculates the additional pipe capacity involved between the before and after models and assigns the pipe size (adjusting to nominal pipe sizes, if necessary). It uses the length attribute of each changed pipe and applies generalized cost estimates to each size of pipe across all changed pipes to give a quick cost estimate for implementing the conveyance improvements for that particular scenario. The results from the cost screening tool were checked by using the detailed costing protocol to estimate the cost for a couple of scenarios. Some changes to the generalized values, within an appropriate range, were made to bring the estimates reasonably close. With hundreds of pipes changing size for some scenarios across various rainfall conditions, the tool served to expedite the screening process.

Operations and Maintenance Data

Information related to the agency's O\&M program helped to identify areas of the system that had known problems (e.g. sewer lining, collapsed sewers, sewer cleaning, other agency knowledge of system). 


\section{SWM Manning's n-values}

The Manning's n-values from the SWM were used to identify locations in the collection system that may need O\&M attention and could possibly provide additional system hydraulic capacity by cleaning of the system and restoring the reach of sewer to more typical n-values. If a reach of sewer in a problem area had a particularly high Manning's roughness coefficient (n-value $>\sim 0.016$ ), then before upsizing any pipes in that area, the n-value was returned to a more typical value and the model re-run to see if the additional flow capacity recovered would eliminate the need to upsize the pipes.

\section{SWM R-Values}

The R-values from the SWM, which represent the percent of rainfall that enters the collection system as I/I, were used to identify areas of the collection system that experience very high $\mathrm{I} / \mathrm{I}$ rates. The R-values correspond to the approximate 80 sanitary sewersheds within the Mill Creek Basin that were analyzed for I/I during the SWM development and corresponded to the typically more wet Spring season (February thru May). The high RDI/I areas, considered as areas with observed R-values greater than $20 \%$, helped direct the evaluation of RDI/I reduction option.

\section{Water-In-Basement Complaints}

The agency provided the locations of customer complaints related to collection system capacity constraints which were an important piece of the planning effort. Using GIS technology, the complaint locations were viewed alongside the hydraulic capacity deficiencies to determine if the resulting water depths in the pipes corresponding to the different alternatives were low enough to not adversely impact the flow coming from the sewer laterals servicing the customers. This was a key component for establishing the effectiveness of the various options evaluated.

\section{Evaluation Criteria}

The team coordinated with the agency on determining the set of evaluation criteria. This was the basis for determining the effectiveness of the various solutions evaluated and provided consistency across all three drainage basins. Two primary criteria were acceptable surcharging in pipes that do not influence service laterals and dewatering times for proposed storage facilities. 


\subsubsection{General Approach}

After compiling and screening the options available for both local and regional solutions, the conveyance option indicated to be the broadest possibility for solving the hydraulic capacity deficiencies. Therefore, the initial option modeled was the conveyance enhancement only option. This involved only expanding the diameters of the sewers wherever there were surcharging conditions, in both the local and regional sections, and thereby eliminating all surcharging within the collection. Some iterative runs were performed to better isolate only the pipes causing the surcharge conditions and changing back to their original sizes those that surcharged only because of downstream hydraulic bottlenecks.

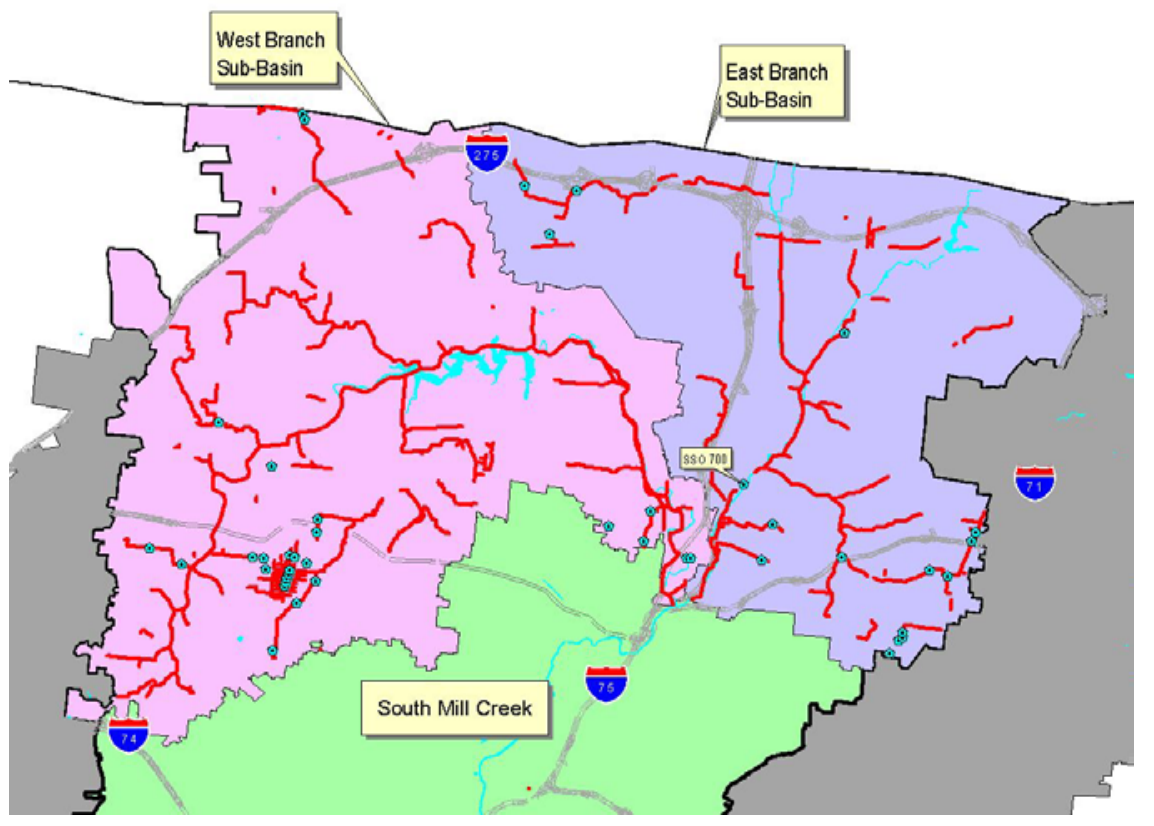

Figure 23.7 Conveyance Enhancement ONLY Option in Sanitary Portion of Mill Creek Basin (dark lines represent upsized pipes).

This approach eliminates the activation of any SSOs at the design storm levels considered as well as the potential for any water-in-basement 
occurrences. However, the resulting increase in peak flow rates at the downstream reaches of the sanitary sewer system was dramatic and would need to be conveyed through the existing interceptor sewers downstream which were already overloaded. A large additional interceptor sewer would be required to convey the additional peak flows further downstream to the existing WWTP, which did not have the capacity to expand sufficiently to accommodate the additional flows. The cost screening tool had the capability to estimate the cost of this larger interceptor sewer, but the costs were separated out from the rest of the upsized system in order to provide a more accurate comparison between scenarios. Figure 23.7 illustrates the pipes upsized in the conveyance enhancement only option across the sanitary portion of the Mill Creek Basin. Essentially the entire regional conveyance system would need to be upsized.

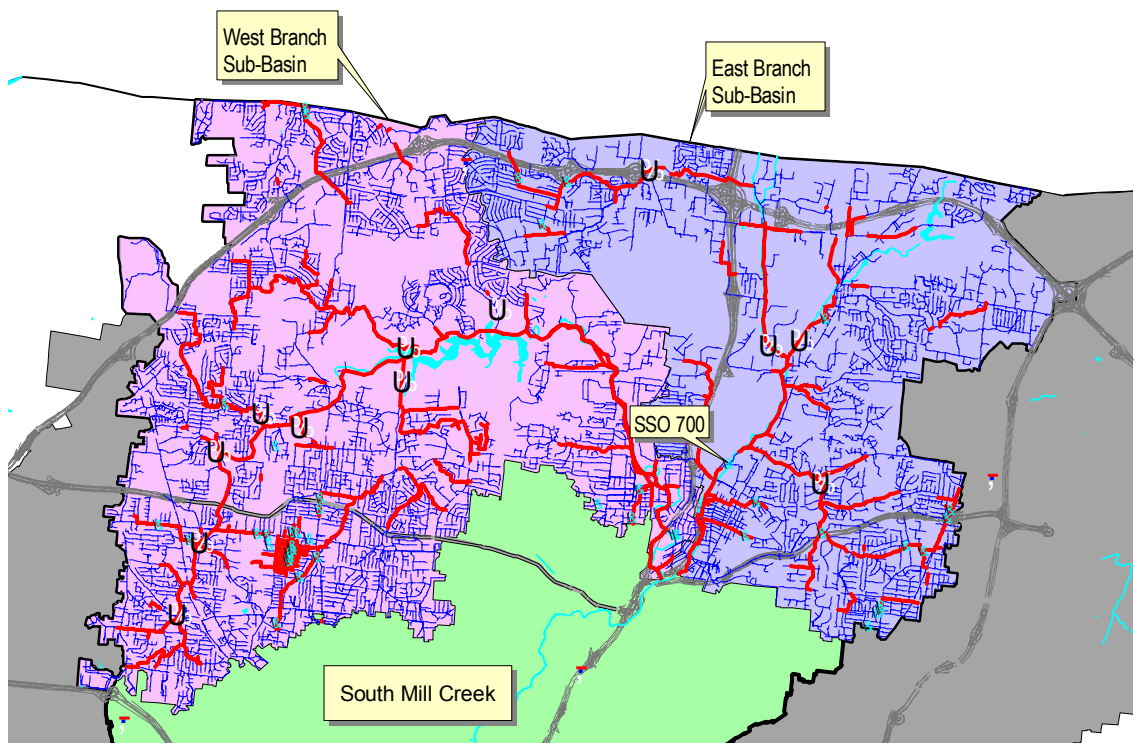

Figure 23.8 Combination of Conveyance Enhancements (thick, dark lines represent upsized pipes) and Initial Storage Facilities (squares) in Sanitary Portion of Mill Creek Basin.

The results from the capacity enhancement only option led to the evaluation of storage up in the system that could attenuate the peak flow rates and thereby avoid the conveyance of additional peak flows to an 
already overloaded downstream interceptor sewer system. Capacity enhancements (i.e. pipe upsizing) remained in the local sections and storage facilities were modeled at the interface of the local and regional sections as well as some along the regional section. No capacity enhancements were made along the regional sections (i.e. trunk sewer remained at their existing pipe diameters). The option was also effective and resulted in the trunk sewer flow rates to be near their capacities at the point where they begin to intercept combined flows further downstream. This option avoided the need to upsize the large trunk sewers located primarily along streams, but resulted in twelve new storage facilities. The approach favored fewer new facilities, if possible, to avoid long-term operations and maintenance issues. Figure 23.8 illustrates the combination of upsized pipes and storage facilities (before consolidation) in the sanitary portion of the Mill Creek Basin.

The next evaluation looked at consolidating the storage facilities while achieving similar results. The result was the reduction of the number of storage facilities to six, most of which became regional storage facilities (i.e. along trunk sewers). This achieved near identical results as the initial storage evaluation involving twelve facilities. Figure 23.9 shows the locations of the consolidated storage facilities in the solution combining capacity enhancements and new storage facilities.

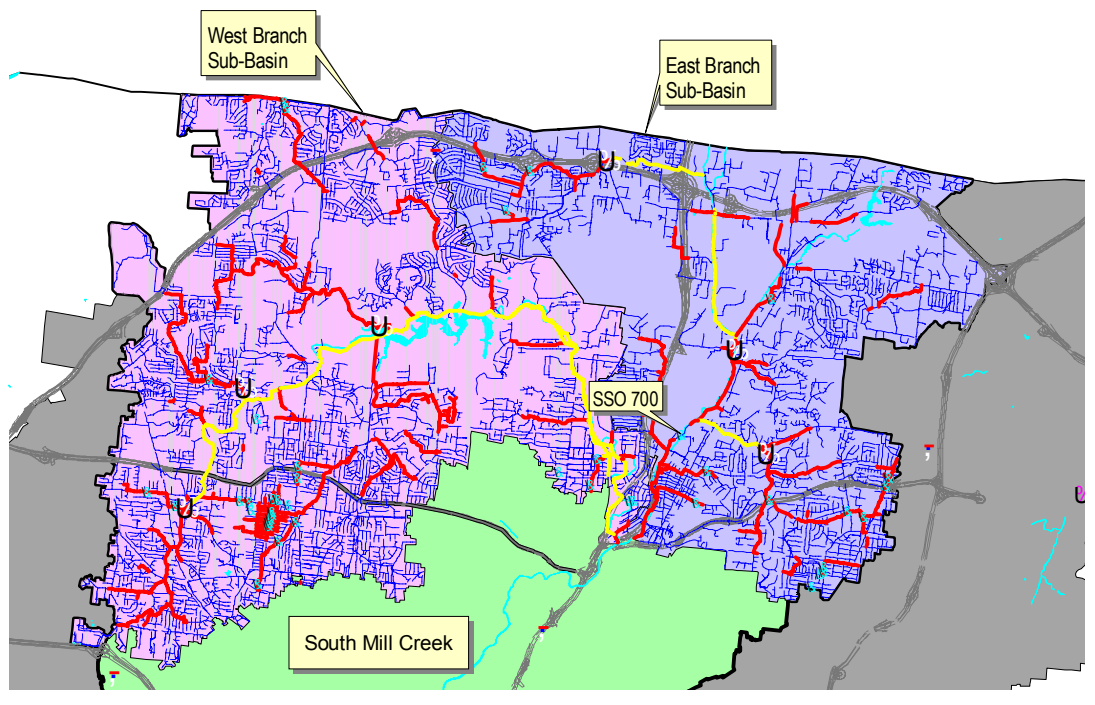

Figure 23.9 Initial Locations of Consolidated Storage Facilities (squares) in Sanitary Portion of Mill Creek Basin. 


\subsubsection{Refinements}

The combination of conveyance enhancements in the local sections and storage facilities primarily in the regional sections was selected as the best possible solution. The refining process looked closely at the initial proposed locations of the storage facilities and at the pipes to be upsized. Remaining options were evaluated to assess their influence on the "front-runner" solution and to determine whether it could be refined. The refining process often involved iterative model runs evaluating various configurations.

\section{Conveyance enhancements}

A review and refinement process of the initial pipes identified to be enhanced considered whether an acceptable surcharge could be accommodated and so avoid the need to upsize certain reaches. The decision to avoid upsizing and accommodate surcharging was based primarily on whether the surcharge conditions posed a potential risk to backing up service connections.

\section{Storage facilities}

The locations of the proposed storage facilities were looked at more closely to determine if a better site could be recommended based on the available planning level information. The topography was also examined to see if it lent itself to the potential of gravity-in, gravity-out storage facilities, which would likely be more cost effective due to the savings in pumping costs.

\section{RDI/I reduction (local option)}

The reduction of inflow and infiltration was modeled to determine its capacity to influence the final solution to the hydraulic capacity deficiencies. $\mathrm{RDI} / \mathrm{I}$ levels were reduced by $20 \%$ and $40 \%$ in the high RDI/I areas only and its influence on the resulting capacity enhancements and storage facilities was assessed. Figure 23.10 shows the areas of high RDI/I, considered as areas that experienced R-values greater than $20 \%$, across the sanitary portion of the Mill Creek Basin.

\section{Pumping (local and regional option)}

Adding additional pumping capacity, either as new facilities or as expansion of existing pumping capacities, was evaluated. The evaluation of the existing, larger pump stations involved the assessment of increasing 
pumping capacity and its influence on the downstream collection system and proposed facilities and maintaining the existing pumping, but expanding the storage capacity at the existing facilities.

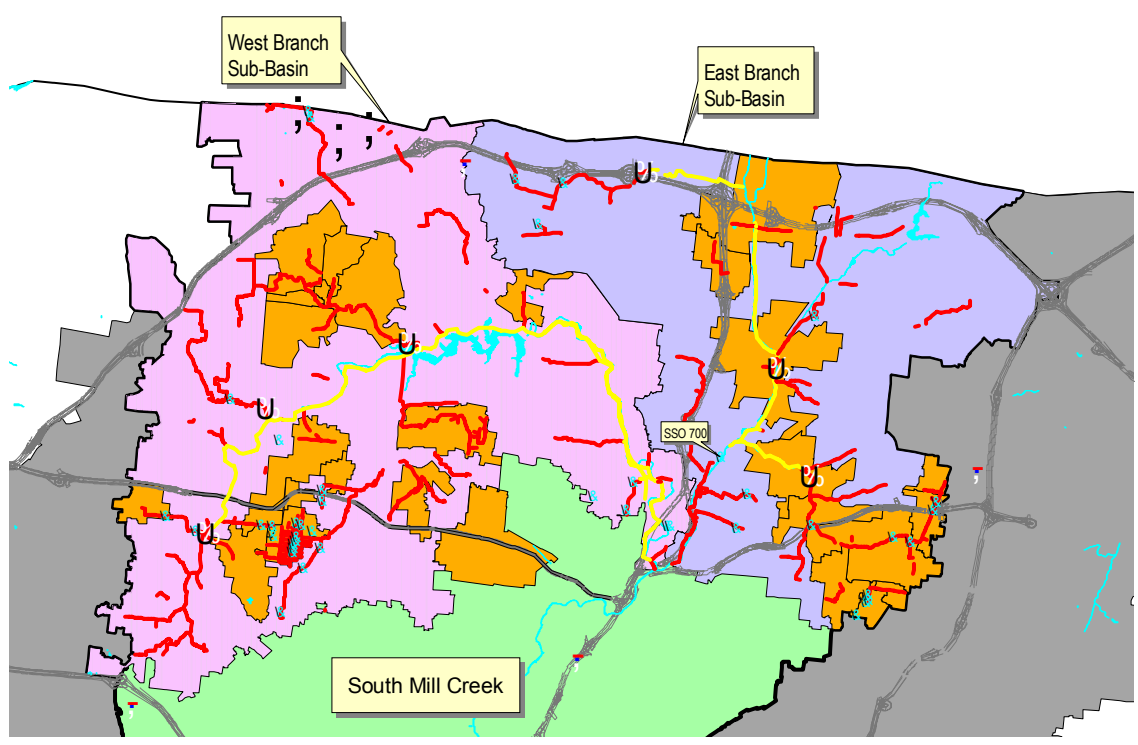

Figure 23.10 Locations of High RDI// Areas (shaded polygons) in Sanitary Portion of Mill Creek Basin.

\section{Tunnel Storage (regional option)}

Replacing the regional storage facilities with a tunnel storage facility was evaluated. This potential refinement offers the advantage of eliminating the proposed new storage facilities, thereby saving on long-term operations and maintenance issues, but proves to be substantially more costly than the surface storage facilities. Figure 23.11 illustrates where tunnel storage was considered as a possible refinement to the solution.

\section{Treatment (primarily regional option)}

Wherever surface or near surface storage facilities were considered, highrate treatment facilities were considered where the flows arriving at the storage sites would be treated and discharged to the receiving water body instead of returning to the collection system to be conveyed downstream to receive full treatment at the existing WWTP. 


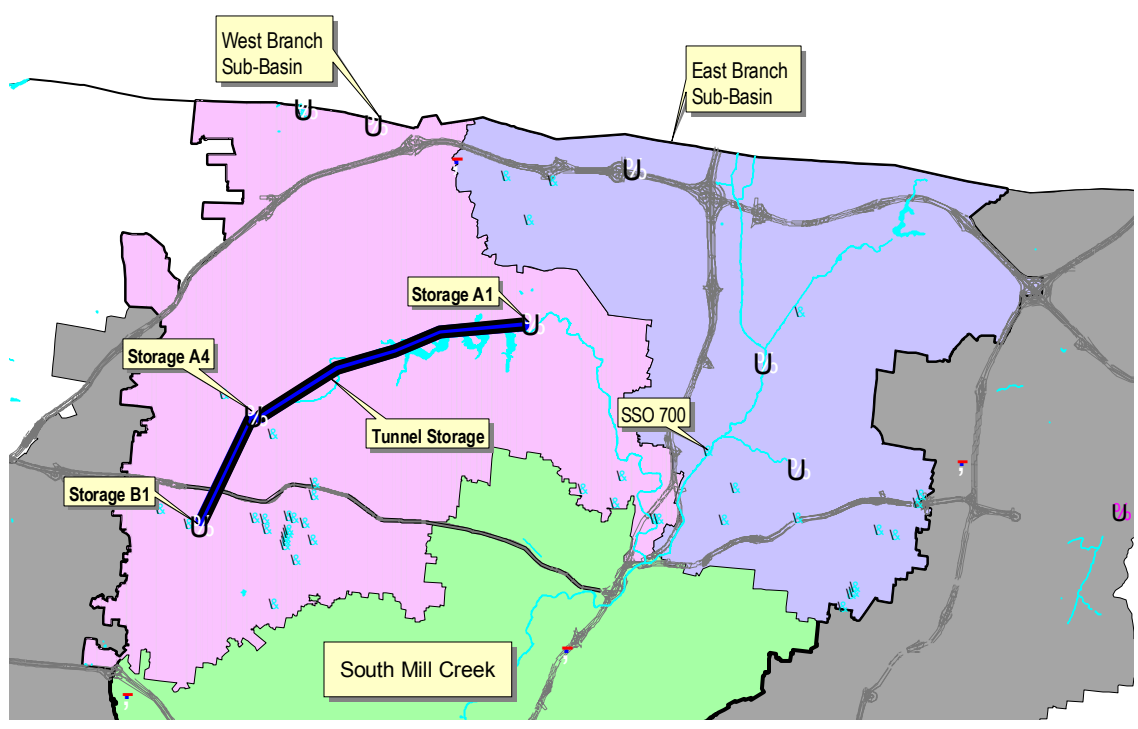

Figure 23.11 Tunnel Storage Consideration (thick, dark lines) to Eliminate Surface Storage Facilities (squares) in the West Branch Sub-Basin of the Mill Creek Basin.

\section{Real-time controls (regional option)}

Real-time controls were considered, but were not found to be of significance in the sanitary areas as little in-line storage capacity was available to take advantage by having a dynamic control system.

The refinement process looked more closely at site specific issues and sought for a more efficient and cost-effective means of solving the associated deficiencies. This refining process continued to narrow the possible solutions to the final recommended solutions.

\subsection{Summary}

The planning process followed for finding solutions to the hydraulic system capacity deficiencies in the sanitary sewer system of the Mill Creek Basin yielded a set of solutions that met the evaluation criteria agreed upon by the 
agency and other team members involved in the other two major drainage basins. A methodical approach was necessary in order to be efficient and stay on schedule with the imminent consent decree deadlines. The study required close coordination with the agency and the other team members involved with the other two major drainage basins in order to assure consistency across the entire collection system study. A host of tools, technologies, and data was employed and integrated to work through the process to arrive at the desired outcome. A few key observations from the planning study are noted:

1. A detailed, fully dynamic System Wide Model greatly facilitated the thorough exploration of solutions. The ability to seamlessly simulate the hydraulic conditions across the entire modeled collection system was critical to the effort. This was important to be able to understand the influence of potential solutions on the downstream system. The effects of the regional and local solutions on each other could be confidently and efficiently evaluated with confidence. The updated SWMM5 software (U.S. EPA, 2002) was found valuable in efficiently and accurately modeling the large collection system (about 24,000 nodes) of the Mill Creek Basin.

2. The organization of the options at regional and local levels helped guide an efficient evaluation process. The compilation of the options table (Table 23.1) and their regional/local possibilities helped identify an evaluation approach that proved efficient and reliable. A relatively clear distinction between regional and local solutions was discovered early in the process. Consequently, solutions to the local problems (in the more upstream reaches of the collection system) did not need to be tampered with while evaluated regional options.

3. The custom planning level costing tool helped expedite the screening process of the various potential solutions. Using only the Costing Protocol for each evaluated solution would have required much more time. Instead, the basic information from the Costing Protocol was incorporated into a tool that could quickly read the model results from any particular run and estimate a cost for that particular solution. This was created for only the conveyance enhancement options, as this option involved a large 
number of pipes to cost. Once the recommended solutions were identified, then the costing of the corresponding projects was estimated based on the more rigorous and detailed costing procedures.

4. The availability and reliability of the necessary information to carry out a successful planning study of this nature that was available through the agency's GIS was a significant advantage.

5. Frequent and accurate communication and coordination with the agency and other team members was vital. The sharing of the findings as the process moved forward helped guide the team's effort and provided consistency. The lack, thereof, would almost certainly have resulted in duplicate efforts and inefficiencies.

This planning-level effort yielded approximately $\$ 300 \mathrm{M}$ in sanitary sewer capital improvement projects that address the hydraulic system capacity deficiencies in the Mill Creek Basin and that are being considered as part of the agency's wet weather improvement plan to meet consent decree requirements.

\section{References}

CAGIS (Cincinnati Area Geographic Information System), http://cagis.hamiltonco.org/CAGIS/.

CDM, 2003. System Wide Model, Executive Summary. March 2003.

Huber, W. C. and R. E. Dickinson (1988). Storm Water Management Model - Version 4: User's Manual; Cooperative Agreement CR-811607; U.S. EPA; Athens, Georgia.

U.S. EPA, 2002. SWMM Redevelopment Project Plan - Version 5; U.S.EPA Office of Research and Development - Water Supply and Water Resources Division; Cincinnati, Ohio; February 19, 2002.

United States of America and the State of Ohio, 2002. Interim Partial Decree on Sanitary Sewer Overflows. United States of America and The State of Ohio vs. the Board of County Commissioners of Hamilton County, Ohio and The City of Cincinnati. Civil Action No. 1:02cv00107.

United States of America, the State of Ohio, and the Ohio River Valley Water Sanitation Commission, 2003. Consent Decree on Combined Sewer Overflows, Wastewater Treatment Plants and Implementation of Capacity Assurance Program Plan For Sanitary Sewer Overflows. United States of America, The State of Ohio, and Ohio River Valley Water Sanitation Commission vs. The Board of County Commissioners of Hamilton County, Ohio and The City of Cincinnati. Civil Action No. C-1-02-107. 